\title{
Influence of stitch length and structure on selected mechanical properties of single jersey knitted fabrics with varying cotton percentage in the yarn
}

\begin{abstract}
In this study, an attempt has been taken to find out the influence of stitch length, knit structure and yarn type on the pilling and abrasion resistance of major weft knitted single jersey fabrics. The knit structures were selected as Plain, Polo pique, Single Lacoste and Double Lacoste made from 30/1 Ne 100\% Cotton, PC (Polyester-Cotton) and CVC (Chief Value of Cotton) yarns with varying the stitch length of $2.59 \mathrm{~mm}, 2.74 \mathrm{~mm}, 2.88 \mathrm{~mm}, 3.02 \mathrm{~mm}$ and $3.16 \mathrm{~mm}$. The results revealed that smaller stitch length promotes both pilling and abrasion properties. It was also found that pilling resistance of Double Lacoste structure was the highest in all types of yarns and stitch lengths although its abrasion resistance was the lowest. Moreover, the fabrics made from $100 \%$ cotton yarns had better pilling performance than blended yarns but its abrasion resistance was the lowest among them.
\end{abstract}

Keywords: plain, polo pique, single lacoste, double lacoste, cotton, polyester-cotton, chief value of cotton, abrasion, pilling
Volume 4 Issue 2 - 2018

\author{
Masudur Rahman ANM \\ Department of Fabric Engineering, Faculty of Textile Engineering, \\ Bangladesh University of Textiles, Bangladesh
}

\begin{abstract}
Correspondence: Masudur Rahman ANM, Lecturer, Department of Fabric Engineering, Faculty of Textile Engineering, Bangladesh University of Textiles (BUTEX), 92, Shahid Tajuddin Ahmed Sarani, Tejgaon I/A, Dhaka-I208, Bangladesh, Tel +8801553342607, Email masudfabric@yahoo.com
\end{abstract}

Received: February 10, 2018 | Published: April 13, 2018

\section{Introduction}

Knitting is a process of manufacturing a fabric by the intermeshing of loops of yarn. Knitted fabric possesses high stretch and recovery, providing greater freedom of movement and outstanding comfort qualities for which they have been preferred as fabrics in many kinds of clothing for a long time. In clothing design and manufacturing, fabric characteristics are usually dictated by a specified end-use. ${ }^{1,2}$

Pilling means the generation of small balls made up of fibers, sometimes with contaminants over the surface of the fabric which give a bad appearance to the garment. Pills are formed during washing, dry cleaning and wearing of knitted goods. The development of pills on a fabric surface, in addition to resulting in an unsightly appearance, initiates the attrition of the garment and can cause premature wear., The process of formation of pills consists of three stages: due to mechanical impact to the surface of rasped products, firstly, the tips of several fibers of fiber are pulled out creating a fuzzy surface. Later, broken fibers grip to felt tips and forms separate, gradually growing pills. Fibers holding these pills are griped strongly, later, however, due to the further mechanical impact (attrition, washing and other) they may rub away and fall off.$^{5}$ Abrasion resistances are the ability of a fabric to resist surface wear caused by flat rubbing contact with another fabric. A fabric may lose its aesthetic appeal due to wear, which is a combined effect of several factors like pilling, abrasion, repeated laundering, the application of forces in dry and wet states, etc. arising from everyday use and service. ${ }^{6-8}$ Abrasion resistance and pilling performance are two of the most important mechanical characteristics of knitted fabrics.

Abrasion resistance is not described by the Textile Institute but is defined by ASTM as the resistance to abrasion, usually stated in terms of a number of abrasion cycles. Academics at Leeds University have described abrasion as "the physical destruction of fibers, yarns, and fabrics, resulting from the rubbing of a textile surface over another surface". Textile materials can be unserviceable because of several different factors and one of the most important causes is abrasion. Abrasion occurs during wearing, using, cleaning or washing process and this may distort the fabric, cause fibers or yarns to be pulled out or remove fibers or yarns to be pulled out or remove fiber ends from the surface. Abrasion ultimately results in the loss of performance characteristics, such as strength, but it also affects the appearance of the fabric. Abrasion resistance of the textile materials is a very complex phenomenon and affected by many factors, mainly classified as follows: Fiber, yarn, fabric properties and finishing processes. Some of these parameters affect fabric surface whereas some of them have an influence on the internal structure of the fabrics. ${ }^{9}$

The main factors that reduce the service life of the garment are heavily dependent on its end use. But especially certain parts of apparel, such as collar, cuffs and pockets are subjected to serious wear in use. Abrasion and pilling is a serious problem for home textiles like as carpets and upholstery fabrics, socks and technical textiles as well. Yarn abrasion is another is another important subject that should be considered during processing. ${ }^{10}$

As knitted fabrics are growingly taking the market of outerwear, consumers are becoming more conscious about fabric quality. Aesthetics are equally as important as the functionality of the textile product. Pilling is originally a fault and the deteriorated surface produced for pilling is undesirable for the customer. Pilling and abrasion resistance are thus a major concern to customers as well as manufacturers. These properties can be influenced by many factors such as stitch length, yarn type, yarn count, knit structure etc. of a knitted fabric..$^{11,12}$

Several works have been reported about the pilling and abrasion behavior of knitted fabrics. In 2010, El-Dessouki showed that the abrasion resistance significantly increases when the polyester ratio increases because of higher tensile strength and bending resistance of polyester fibers. So, it was found that 50/50 Cotton/Polyester blend has the higher abrasion resistance than other cotton/polyester blends. ${ }^{13}$ 
The aim of the present work is to investigate the effect of stitch length, yarn type and knit structure over pilling and abrasion performance of the four major single jersey structures produced in Bangladesh.

\section{Materials and methods}

The study was carried out by producing the following samples sequentially (Table 1).

In total 60 samples were produced to carry out the experiment. Stitch length was maintained by adjusting the diameter of VDQ (Variable Diameter Quality) pulley. The specification of circular knitting machine is given Table 2.

Table I Fabrication of the samples

\begin{tabular}{|c|c|c|}
\hline Fabric type & Yarn type & Stitch length $(\mathrm{mm})$ \\
\hline \multirow{15}{*}{ Plain } & \multirow{5}{*}{ Cotton Combed 30/I Ne } & 2.59 \\
\hline & & 2.74 \\
\hline & & 2.88 \\
\hline & & 3.02 \\
\hline & & 3.16 \\
\hline & \multirow{5}{*}{$\begin{array}{l}\text { CVC Combed 30/I Ne } \\
\text { (Cotton 63\%, Polyester } \\
37 \%)\end{array}$} & 2.59 \\
\hline & & 2.74 \\
\hline & & 2.88 \\
\hline & & 3.02 \\
\hline & & 3.16 \\
\hline & \multirow{5}{*}{$\begin{array}{l}\text { PC Combed 30/I Ne } \\
\text { (Polyester 67.5\%, Cotton } \\
32.5 \% \text { ) }\end{array}$} & 2.59 \\
\hline & & 2.74 \\
\hline & & 2.88 \\
\hline & & 3.02 \\
\hline & & 3.16 \\
\hline \multirow{15}{*}{ Polo Pique } & \multirow{5}{*}{ Cotton Combed 30/I Ne } & 2.59 \\
\hline & & 2.74 \\
\hline & & 2.88 \\
\hline & & 3.02 \\
\hline & & 3.16 \\
\hline & \multirow{5}{*}{$\begin{array}{l}\text { CVC Combed 30/I Ne } \\
\text { (Cotton 63\%, Polyester } \\
37 \% \text { ) }\end{array}$} & 2.59 \\
\hline & & 2.74 \\
\hline & & 2.88 \\
\hline & & 3.02 \\
\hline & & 3.16 \\
\hline & \multirow{5}{*}{$\begin{array}{l}\text { PC Combed 30/I Ne } \\
\text { (Polyester 67.5\%, Cotton } \\
32.5 \% \text { ) }\end{array}$} & 2.59 \\
\hline & & 2.74 \\
\hline & & 2.88 \\
\hline & & 3.02 \\
\hline & & 3.16 \\
\hline
\end{tabular}

\begin{tabular}{|c|c|c|}
\hline & & 2.59 \\
\hline & & 2.74 \\
\hline & Cotton Combed 30/I Ne & 2.88 \\
\hline & & 3.02 \\
\hline & & 3.16 \\
\hline & & 2.59 \\
\hline & CVC Combod 30/L & 2.74 \\
\hline Single & (Cotton 63\%, Polyester & 2.88 \\
\hline & $37 \%)$ & 3.02 \\
\hline & & 3.16 \\
\hline & & 2.59 \\
\hline & PC Combed $30 / 1 \mathrm{Ne}$ & 2.74 \\
\hline & (Polyester 67.5\%, Cotton & 2.88 \\
\hline & $32.5 \%)$ & 3.02 \\
\hline & & 3.16 \\
\hline & & 2.59 \\
\hline & & 2.74 \\
\hline & Cotton Combed 30/I Ne & 2.88 \\
\hline & & 3.02 \\
\hline & & 3.16 \\
\hline & & 2.59 \\
\hline & CVC Combed $3011 \mathrm{Ne}$ & 2.74 \\
\hline $\begin{array}{l}\text { Double } \\
\text { Lacoste }\end{array}$ & (Cotton 63\%, Polyester & 2.88 \\
\hline & $3 / \%)$ & 3.02 \\
\hline & & 3.16 \\
\hline & & 2.59 \\
\hline & PC Combed 30/I Ne & 2.74 \\
\hline & (Polyester 67.5\%, Cotton & 2.88 \\
\hline & $32.5 \%)$ & 3.02 \\
\hline & & 3.16 \\
\hline
\end{tabular}

Table 2 Specification of the Circular knitting machine

\begin{tabular}{ll}
\hline Name of the machine & Single jersey circular knitting machine \\
\hline Machine Gauge & $24 \mathrm{G}$ \\
Cylinder Diameter & 10 inch \\
No. of Feeders & 30 \\
No. of Tracks & 4 \\
Total No. of Needles & 744 \\
Type of Needle & Latch Needle \\
Creel Capacity & 64
\end{tabular}


Martindale Abrasion and Pilling Tester, SDL International (Model M 235, England) were used to measure abrasion and pilling resistance of the fabrics.

\section{Pilling procedure}

After preparing the samples, the pilling test was performed according to ISO 12945-1:2000. ${ }^{13}$ Before testing, the samples were conditioned at standard temperature $\left(20 \pm 2^{\circ} \mathrm{C}\right)$ and relative humidity of $(65 \pm 2 \%)$ for $24 \mathrm{hrs}$. After preparation, the samples were subjected to multi-directional rubbing for 125,500 and 2000 cycles. After each completed cycle the samples were brought under sufficient light and compared to standard photographs and grading was done. The grading system for visual pilling assessment authorized by ISO is given in Table 3. The samples are then given a rating between 1-5 by using photographic assessment. ${ }^{14}$

Table 3 The visual assessment for pilling grade. ${ }^{14}$

\begin{tabular}{ll}
\hline Grade & Description \\
\hline 5 & No change \\
4 & Slight surface fuzzing and/or partially formed pills \\
& $\begin{array}{l}\text { Moderate surface fuzzing and/or moderate pilling. Pills of } \\
\text { varying size and density partially covering the specimen } \\
\text { surface }\end{array}$ \\
& $\begin{array}{l}\text { Distinct surface fuzzing and/or distinct pilling, pills of } \\
\text { varying size and density covering a large proportion of } \\
\text { the specimen surface }\end{array}$ \\
& $\begin{array}{l}\text { Dense surface fuzzing and/or severe pilling, pills of } \\
\text { varying size and density covering a whole of the } \\
\text { specimen surface }\end{array}$ \\
\hline
\end{tabular}

\section{Abrasion procedure}

Martindale tester is designed to give a controlled amount of abrasion between fabric surfaces at comparatively low pressures in continuously changing direction. The abrasion resistance of the fabrics was tested on the Martindale pilling and abrasion tester at 9KPa pressure according to ISO 12947-3:1999. A circular specimen $(38 \mathrm{~mm})$ mounted in a specimen holder and subjected to a defined load, is rubbed against an abrasive medium in a translational movement tracing a Lissajous figure, the specimen holder being additionally freely rotatable around its own axis perpendicular to the plane of the specimen. The evaluation of the abrasion resistance is determined from the mass loss of specimen after specific amount $(100,250,500,750$ and 1,000 cycles) of rubs. ${ }^{15}$

\section{Results and discussions}

Pilling studies have shown that there are three distinct stages in the life span of a pill. First, fibers are surfaced as a result of some mechanical action on the fabric. Second, surface fibers entangle or mat into the familiar configuration of a pill. Finally, the pill may be worn or pulled away from the fabric. In a given fabric construction, the rate or extent to which these stages occur is determined by the physical properties of the fibers which comprise the fabric. By determining those properties which operate in the fuzz formation, entanglement and pill break off steps, an understanding of the overall mechanism of pilling can be achieved. ${ }^{16}$

\section{Effect of stitch length on pilling resistance}

The data presented in Figures 1-3 show the effect of stitch length on pilling resistance. Keeping other factors constant, it was observed that the pilling resistance varied very little due to the change in stitch length of fabric. It was seen that the pilling resistance decreased with increase in stitch length. This trend is similar for all knitted structures. In Polo Pique cotton fabric, the highest resistance (grade-4) was found at the stitch length of $2.59 \mathrm{~mm}, 2.74 \mathrm{~mm}$ and $2.8 \mathrm{~mm}$. The lowest resistance (grade 3.5) was found at stitch length $3.02 \mathrm{~mm}$ and $3.16 \mathrm{~mm}$. The fabric of lower stitch length was knitted more tightly and its stitch density increased. This restrained the loops from moving, leading to increasing in pilling resistance.

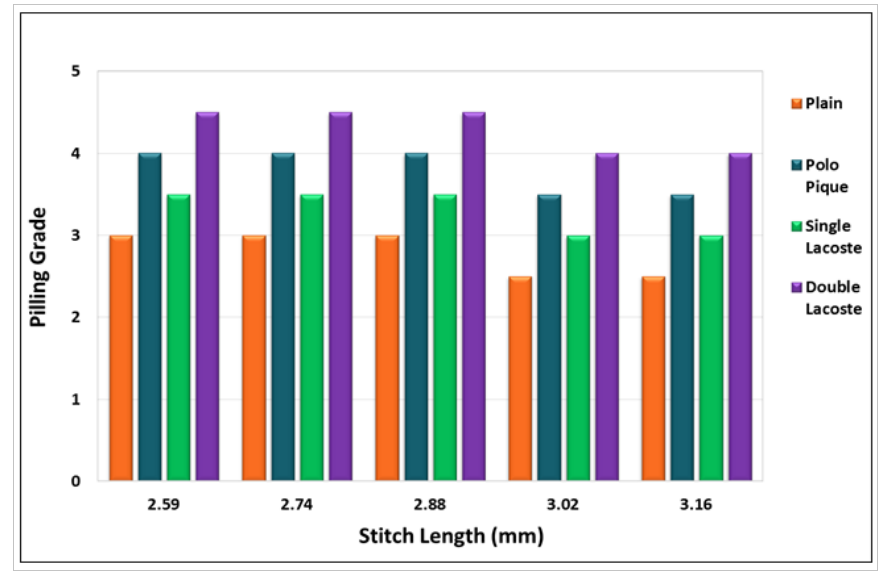

Figure I Pilling resistances of 100\% cotton fabrics at different stitch length after 2000 cycle.

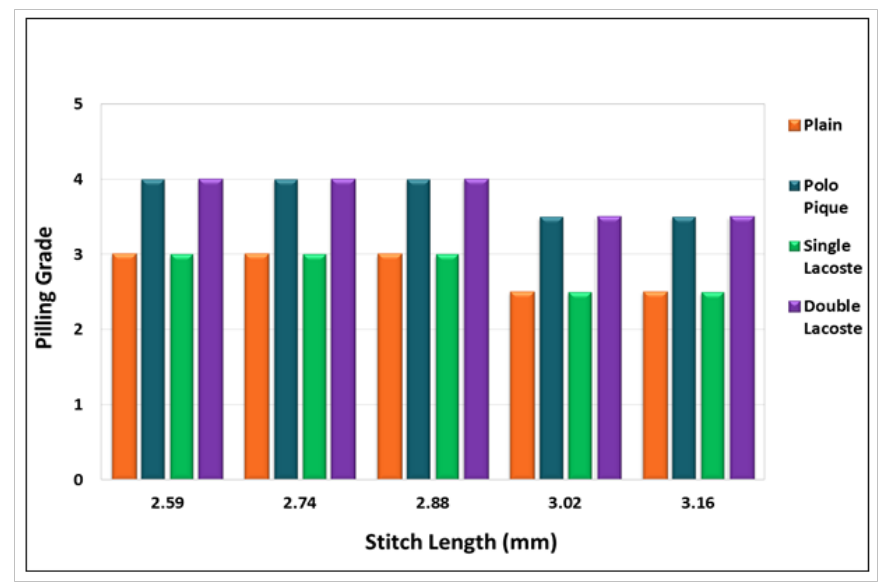

Figure 2 Pilling resistances of PC fabrics at different stitch length after 2000 cycle.

\section{Effect of knitted structures on pilling resistance}

The effect of knitted structures on the pilling resistance of fabrics can be seen in Figures 4-8. The Double Lacoste structures showed highest pilling resistance while the Plain structures showed the lowest. In $100 \%$ cotton fabrics of stitch length $2.59 \mathrm{~mm}$, the highest pilling grade (4.5) was found in Double Lacoste fabric and the lowest grade (3) was in the Plain fabric. Double Lacoste structure had a rough surface due to motifs. For this, it was subjected to more frictional forces and more pilling occurred. However, the rate of pill wear-off 
was more than the rate of pill formation and fewer pills remained on the fabric surface. In Plain fabrics, ideal loop configurations were formed. As a result, an abrading area in Plain fabrics was greater than the other structures.

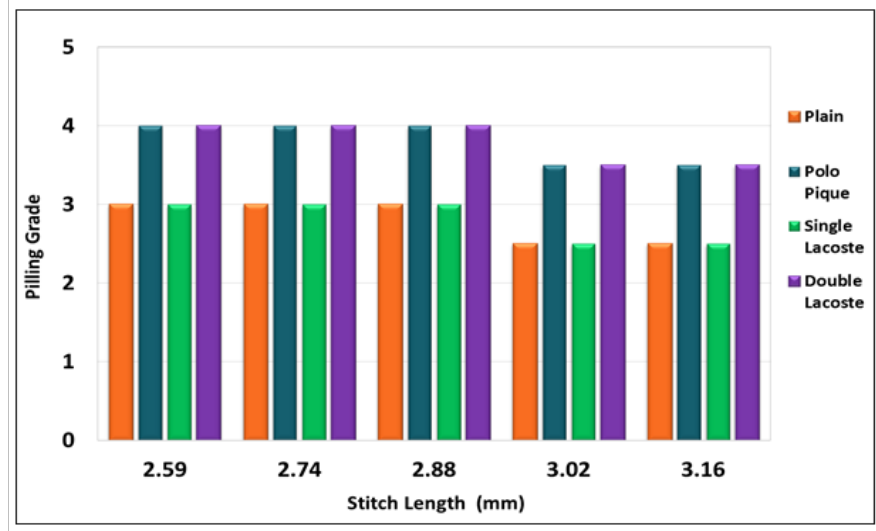

Figure 3 Pilling resistances of CVC fabrics at different stitch length after 2000 cycle.

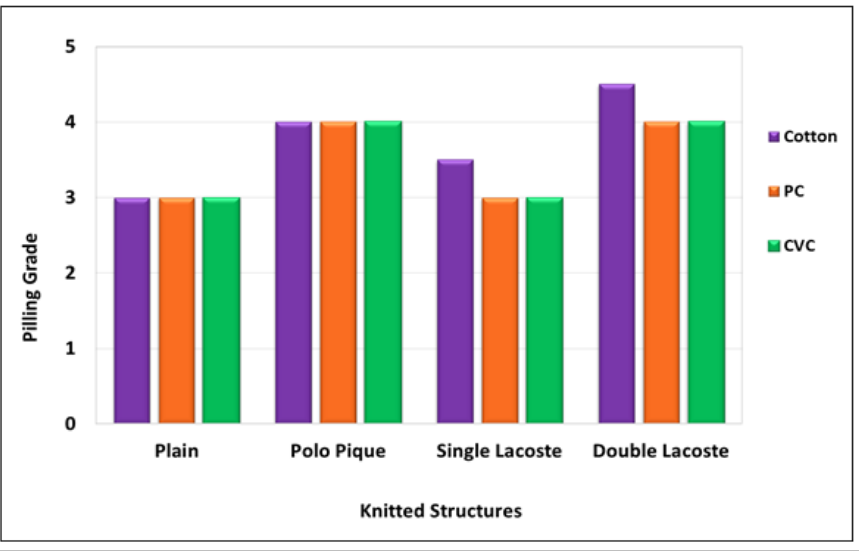

Figure 4 Pilling resistances of different structures for stitch length of $2.59 \mathrm{~mm}$.

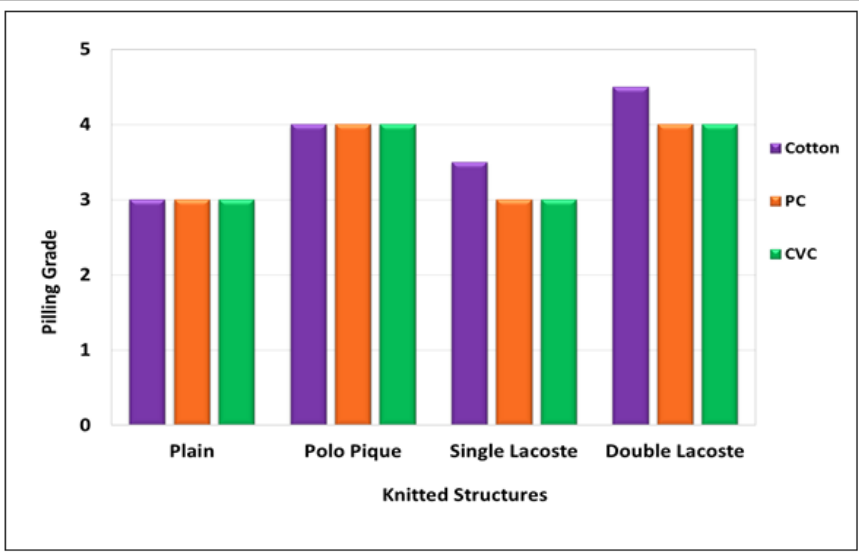

Figure 5 Pilling resistances of different structures for stitch length $2.74 \mathrm{~mm}$.

\section{Effect of yarn types on pilling resistance}

The data in Figures 9-12 clearly show the effect of yarn type on pilling resistance. It was found that knits from $100 \%$ cotton yarns had better resistance than those from blended yarns (PC \& CVC). In Double Lacoste fabrics at stitch length, $2.59 \mathrm{~mm}$ the highest pilling resistance (grade-4.5) was in Cotton fabrics and lowest resistance (grade-4) was in PC and CVC fabrics. Due to the higher rate of pill wear-off than the rate of pill formation in Cotton fabrics, the amount of visible pills on the fabric surface was less, leading to a higher pilling grade. The fabrics made of blended yarns also formed pills but pills were securely anchored to the polyester fibers which did not easily break off due to higher strength. For this, the pills did not fall off from the fabric surface.

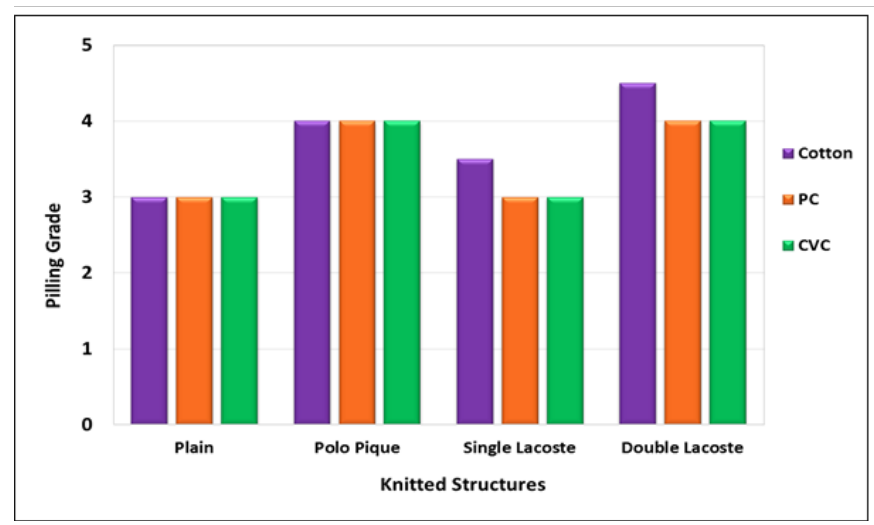

Figure 6 Pilling resistances of different structures for stitch length $2.88 \mathrm{~mm}$.

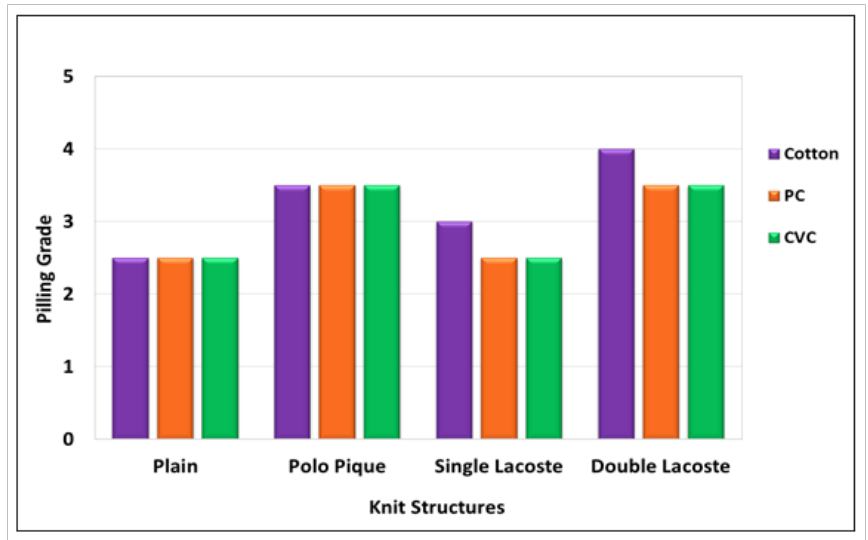

Figure 7 Pilling resistances of different structures for stitch length $3.02 \mathrm{~mm}$.

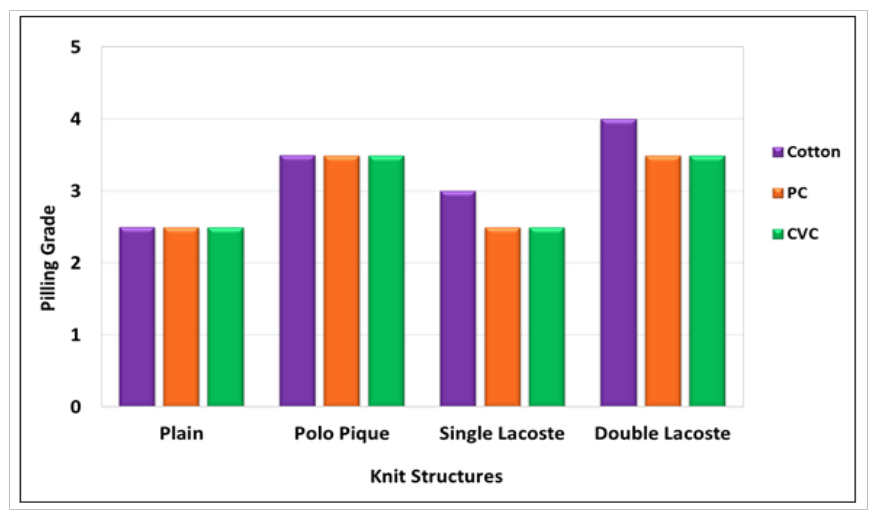

Figure 8 Pilling resistances of different structures for stitch length $3.16 \mathrm{~mm}$. 


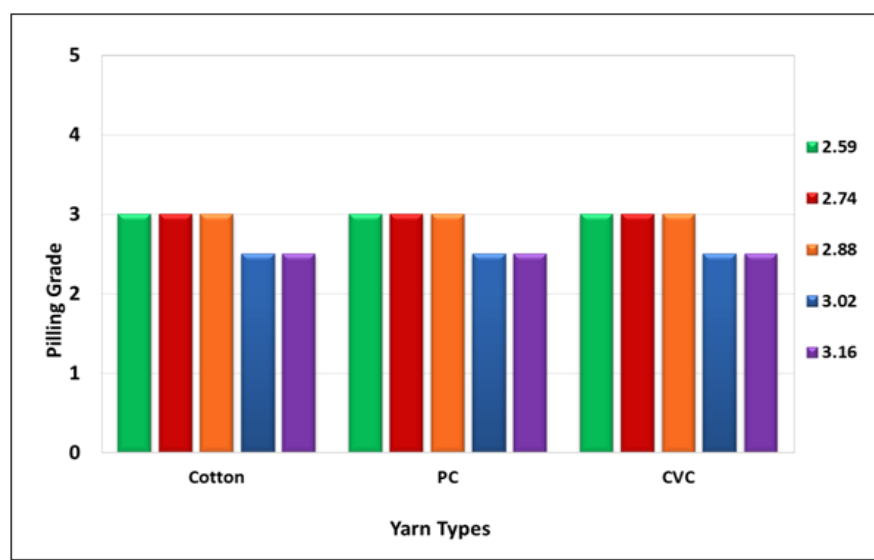

Figure 9 Pilling resistance of plain structure for different yarn type.

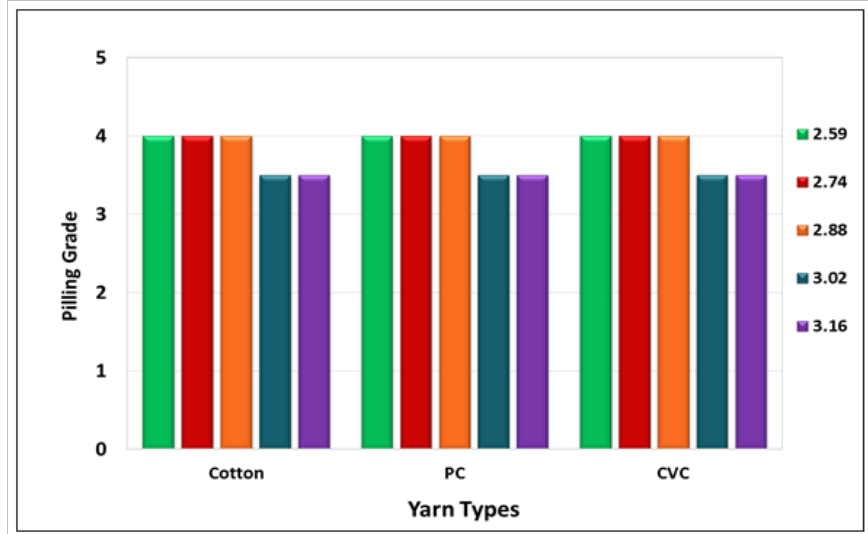

Figure 10 Pilling resistance of polo pique structure for different yarn type.

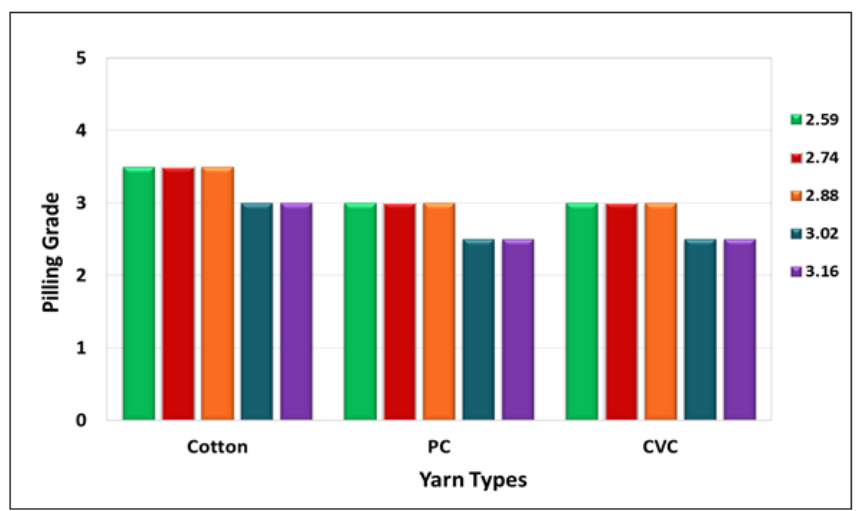

Figure I I Pilling resistance of single lacoste structure for different yarn type.

\section{Effect of stitch length on abrasion resistance}

The data presented in Figures 13-15 show the effect of stitch length on abrasion resistance of the fabrics. It was observed that the mass loss \% increased with increase in stitch length in all types of fabrics. In Plain cotton fabrics, the lowest mass loss $(1.92 \%)$ was at stitch length $2.59 \mathrm{~mm}$ and highest mass loss $(2.72 \%)$ was at stitch length $3.16 \mathrm{~mm}$. Thus smaller stitch length resulted in higher resistance to abrasion. When the stitch length was smaller, the loops were more tightly packed which did not allow fibers to be easily pulled out of the surface of the yarn. A looser structure, made from larger stitch length, had lower abrasion resistance because it was easier to pull the fibers from the yarn surface.

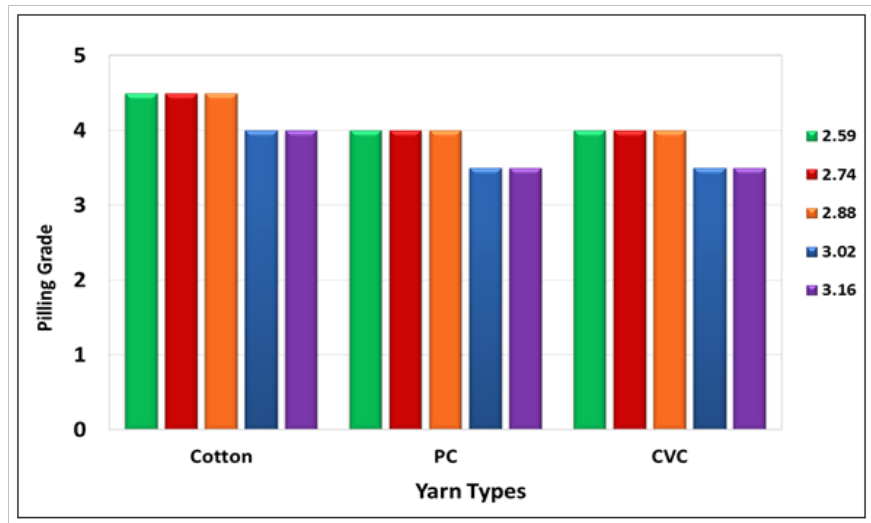

Figure 12 Pilling resistance of double lacoste structure for different yarn type.

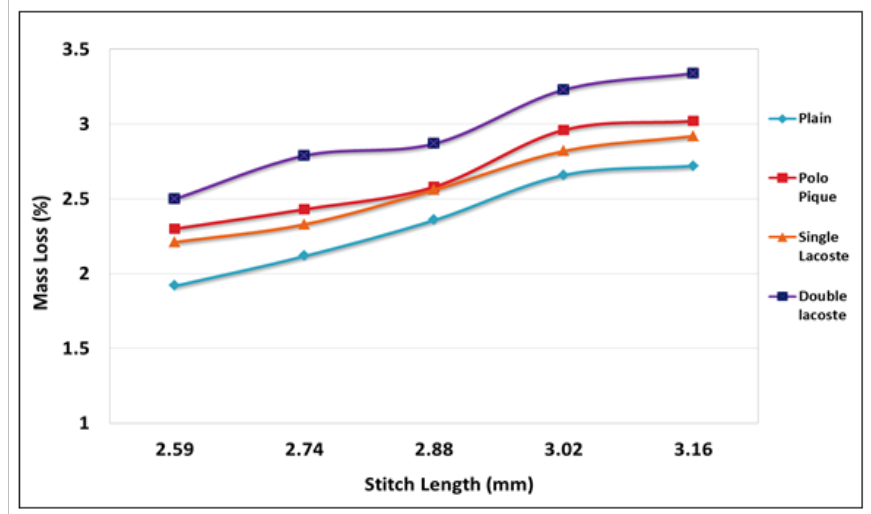

Figure 13 Abrasion resistance of 100\% cotton fabric for different stitch length.

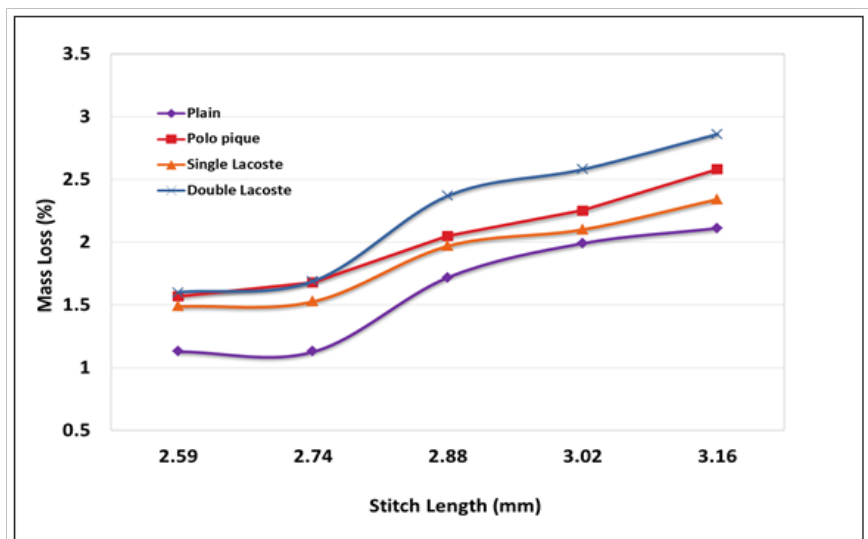

Figure 14 Abrasion resistance of PC fabric for different stitch length.

Course length for the knitted fabrics is so important that the weight loss percent after abrasion increases with increasing course length. Open, slack knitted fabric structure is abraded more than denser fabrics. Thread density is an important parameter that affects the abrasion of the fabric. The more yarns per unit area which can be obtained by using lower stitch length in a fabric, hence the less 
force to each individual thread and therefore the fabrics with a tight structure have higher abrasion resistance than those with a loose structure. However, as the threads become jammed together they are unable to deflect under load and thus absorb the distortion. ${ }^{16}$

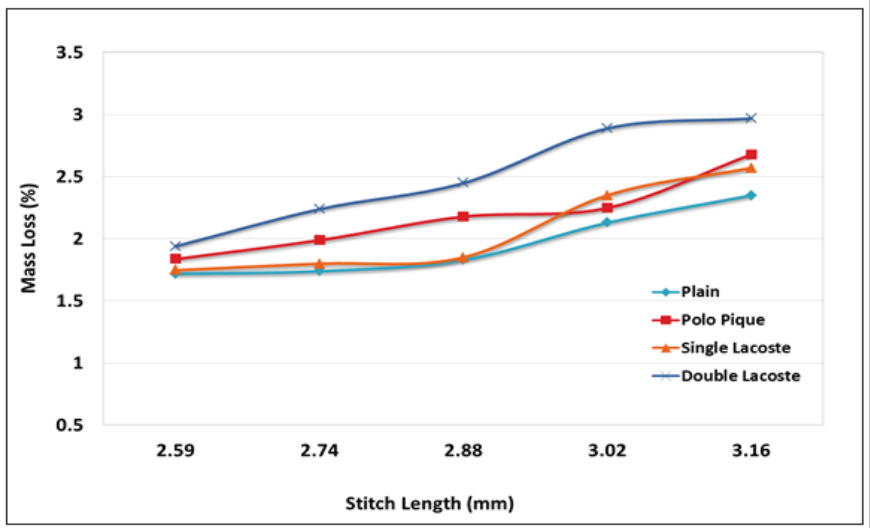

Figure I5 Abrasion resistance of CVC fabric for different stitch length.

\section{Effect of knitted structures on abrasion resistance}

The influence of knit structure on abrasion resistance is apparent from the data presented in Figures 16-20. It was evident that mass loss was highest in Double Lacoste fabrics and lowest in Plain fabrics. In cotton fabrics of stitch length $2.59 \mathrm{~mm}$, Plain fabric had the lowest mass loss $(1.92 \%)$ and Double Lacoste fabric had the highest mass loss $(2.50 \%)$. Double Lacoste fabric had a rough surface to which it was subjected to more frictional forces and more fiber wear-off occurred. Therefore, its abrasion resistance decreased. In Plain fabric, consisting of all knit loops, the fibers were not easily pulled out of the yarn. So, the abrasion resistance was high.

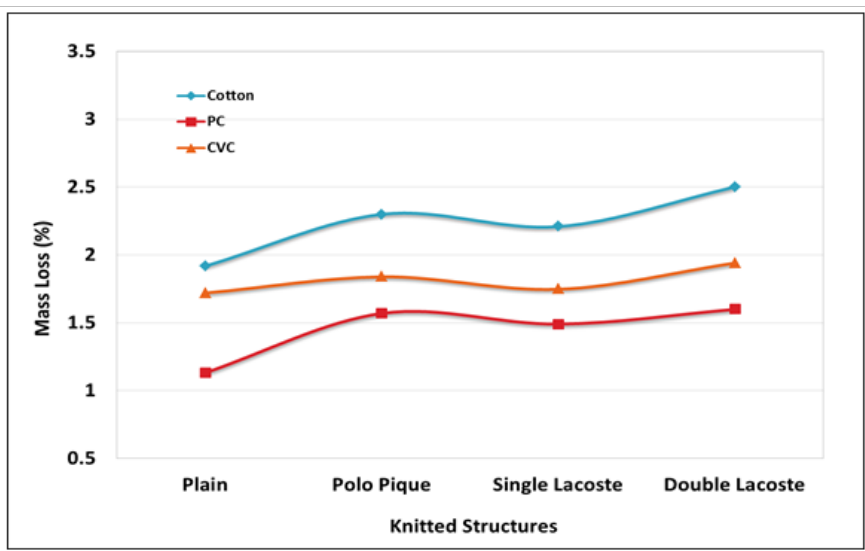

Figure 16 Abrasion resistances of different structures for stitch length $2.59 \mathrm{~mm}$.

Fabric construction, thickness, weight, the number of yarn (thread density) and interlooping per unit area are the fabric properties affecting abrasion. Average abrasion resistance values of plain knitted fabrics are higher than other fabrics. The reason of that is more stable, thicker and voluminous structure of the plain knitted fabrics due to the presence of more knit loops than others. So, fabric mass per square meter and fabric thickness is higher than others. Higher values of these factors ensure higher abrasion resistance. ${ }^{17}$

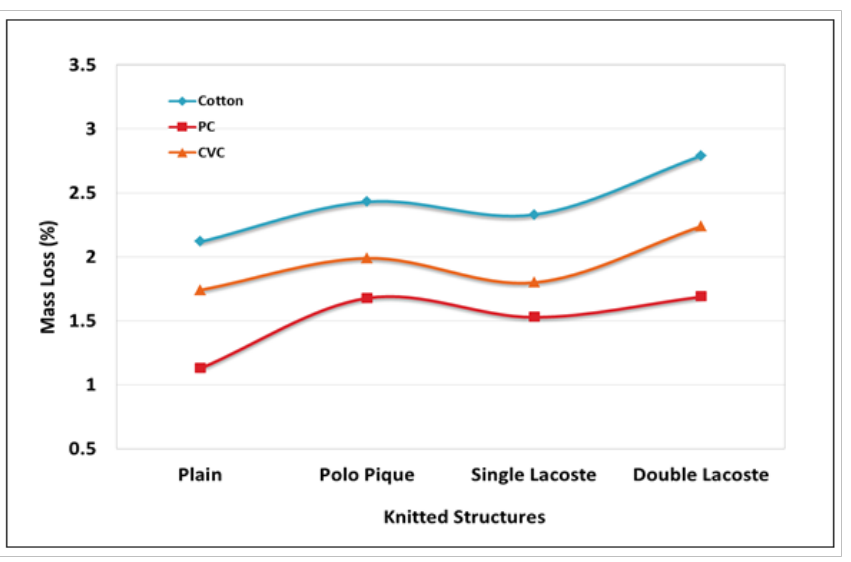

Figure 17 Abrasion resistances of different structures for stitch length $2.74 \mathrm{~mm}$

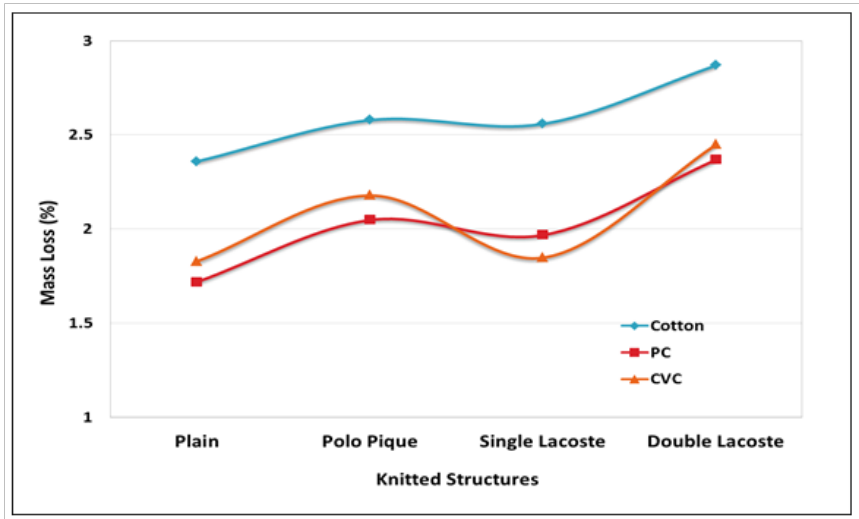

Figure 18 Abrasion resistances of different structures for stitch length $2.88 \mathrm{~mm}$.

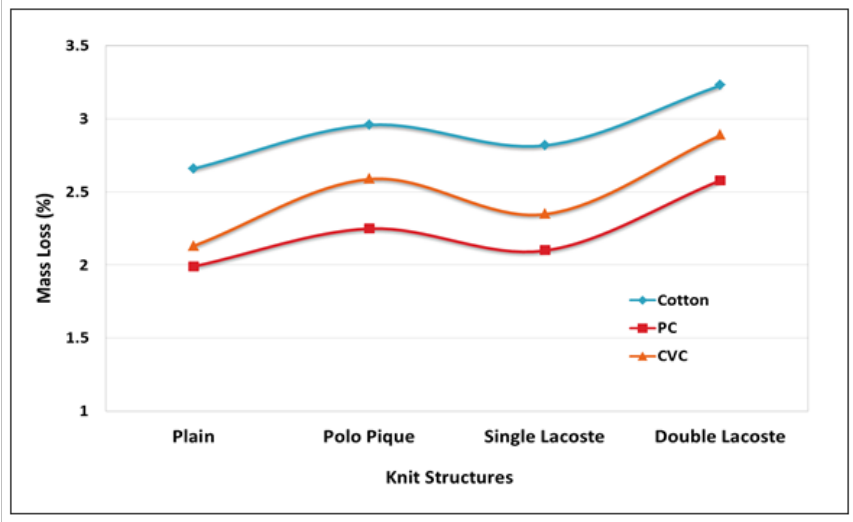

Figure 19 Abrasion resistances of different structures for stitch length $3.02 \mathrm{~mm}$.

\section{Effect of yarn types on abrasion resistance}

The data presented in Figures 21-24 show the effect of different yarn types on the abrasion resistance of the fabric. Cotton fabrics had the highest mass loss \% followed by CVC and PC respectively. 
For Plain fabrics at stitch length $2.59 \mathrm{~mm}$, the mass loss was $1.13 \%$ (highest) in PC fabric, $1.72 \%$ in CVC fabric and $1.92 \%$ (lowest) in cotton fabric. Since cotton fibers were very hairy, they had high tendency to be pulled out of the surface by frictional forces. Thus more mass loss occurred in those fabrics where the yarn had a higher percentage of cotton fibers.

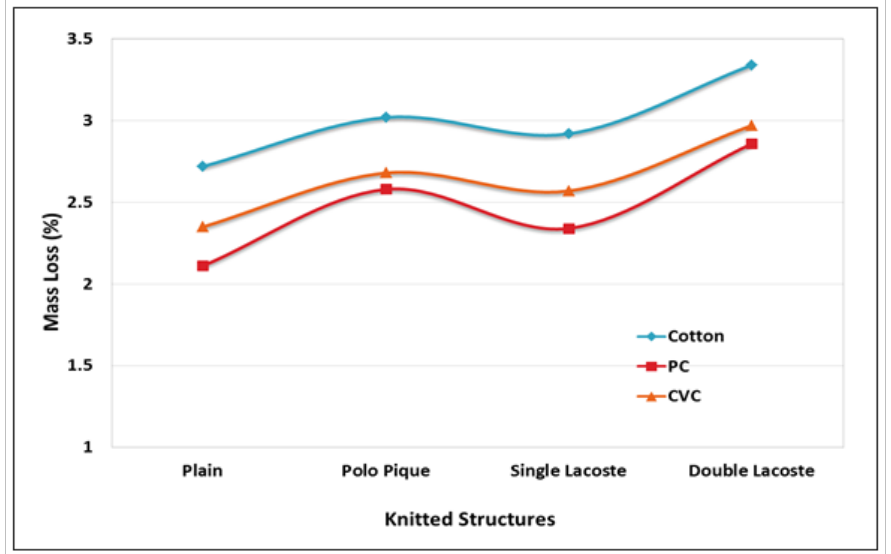

Figure 20 Abrasion resistances of different structures for stitch length $3.16 \mathrm{~mm}$.

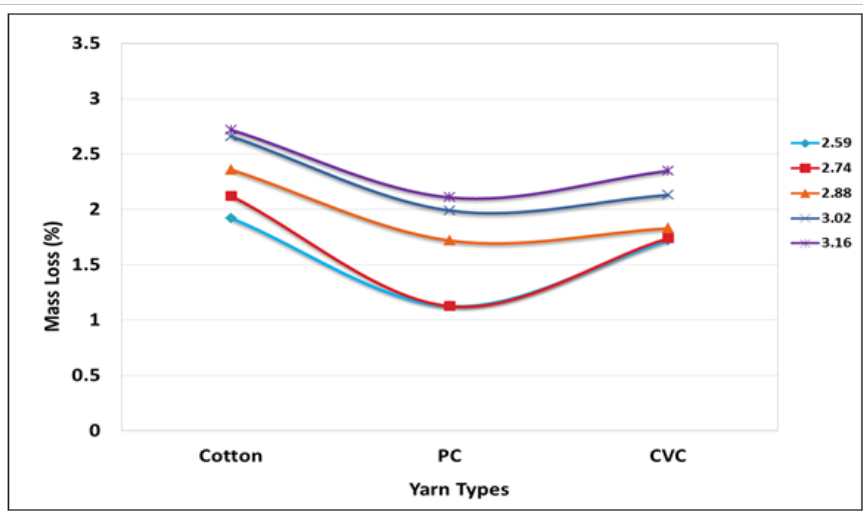

Figure 2I Abrasion resistances of plain structure for different fiber types.

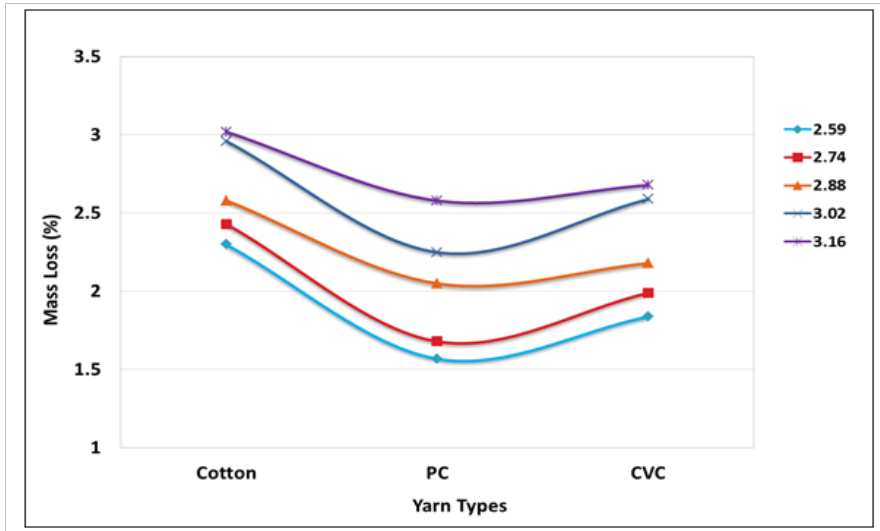

Figure 22 Abrasion resistances of polo pique structure for different yarn types.

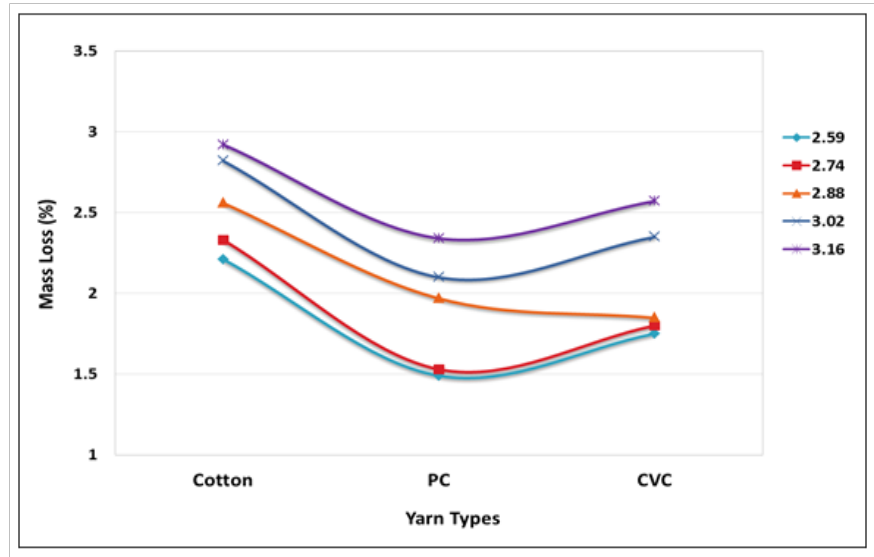

Figure 23 Abrasion resistances of single lacoste structure for different yarn types.

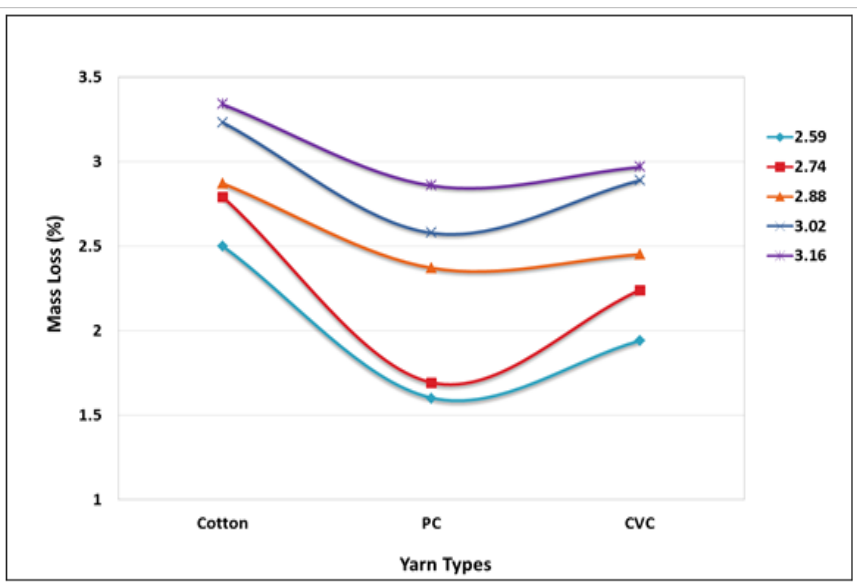

Figure 24 Abrasion resistances of double lacoste structure for different yarn types.

The mechanical properties and dimensions of the fibers are important for abrasion. Fiber type, fiber fineness and fiber length are the main parameters that affect abrasion. Fibers with high elongation, elastic recovery and work of rupture have a good ability to withstand repeated distortion; hence a good degree of abrasion resistance is achieved. Polyester is generally considered to have the best abrasion resistance. ${ }^{18}$ Blending of polyester with cotton is found to increase abrasion resistance at the expense of other properties. The higher cotton rate increases the mass loss. However, synthetic fibers are produced in many different versions so that the abrasion resistance of particular variant may not conform to the general ranking of fibers. The removal of the fibers from yarn structure is one of the reasons of the abrasion. Therefore factors that affect the cohesion of yarns will influence the abrasion resistance of fabrics as well. Longer fibers incorporated into a fabric confer better abrasion resistance than short fibers because it is harder to liberate them from the fabric structure. For the same reason filament yarns are more abrasion resistant than staple yarns made from the same fiber. ${ }^{16,18}$ For these reasons the fabric made of PC yarn shows the highest and the fabric made of $100 \%$ cotton yarn shows the least abrasion resistance. 


\section{Conclusion}

The results show that both fabric structure and yarn type play a vital role in determining the pilling and abrasion resistance of these fabrics while stitch length does not have a significant effect on them.

It is apparent that knits from blended yarns have a lower pilling resistance compared to fabrics from $100 \%$ cotton yarns but the opposite is seen in case of abrasion resistance. PC fabrics show the best resistance to abrasion.

Fabrics of Double Lacoste structure show the most pilling resistance and least abrasion resistance followed by Polo Pique, Single Lacoste and Plain structures respectively. Moreover, it can be concluded that higher stitch length lowers both the pilling and abrasion resistance of the fabric even though the change is of only half a grade.

The values obtained in this study can be used to predict the pilling and abrasion resistance of single jersey fabrics during their production in the practical field. Rejection can be reduced by using proper selection of stitch length, yarn type and knit structure for the desired pilling and abrasion performance of the fabric.

\section{Acknowledgments}

The author would like to thank the authority of Ahsanullah University of Science and Technology, Dhaka, to permit and the staffs of the laboratories for their help to carry out the experiment.

\section{Conflict of interest}

Author declare there is no conflict of interest in publishing the article.

\section{References}

1. Chen Y, Collier BJ. Characterizing fabric end use by fabric physical properties. Text Res J. 1997;67(4):247-252.

2. Emirhanova N, Kavusturan Y. Effects of knit structure on the dimensional and physical properties of winter outerwear knitted fabrics. Fibers \& Textiles in Eastern Europe. 2008;16(2):69-74.

3. Gintis D, Mead EJ. The mechanism of pilling. Text Res J. 1959;29(7):578585
4. Manich AM, De Castellar MD, Sauri RM, et al. Abrasion kinetics of wool and blended fabric. Text Res J. 2001;71(6):469-474.

5. Busiliene G, Lekeckas K, Urbelis V. Pilling resistance of knitted fabrics Materials Science. 2011;17(3): 297-301.

6. Candan C, Önal L. Dimensional, pilling and abrasion properties of weft knits made from open-end and ring spun yarns. Text Res $J$ 2002;72(2):164-169.

7. Rangulam RB, Amirbayat J, Porat I. The objective assessment of fabric pilling part 1: methodology. J Text Inst. 1993;84(2):221-226.

8. Sivakumar VR, Pillay KPR. Study of pilling on polyester/cotton blended fabrics. Indian J of Text Res. 1981;6(1):22-27.

9. Hsi $\mathrm{CH}$, Bresee RR, Annis PA. Characterizing fabric pilling by using image-analysis techniques. Part I: Pill detection and description. $J$ Text Inst. 1998;89(1):80-95.

10. Abdullah I, Blackburn RS, Russell S J, et al. Abrasion phenomena in twill tencel fabric. J Applied Polym Sci. 2006;102(2):1391-1398.

11. Okudayashi S, Campos R, Rohrer C, et al. Pilling mechanism for cellulosic knit fabrics-effects of wet processing. J Text Inst. 2005;96(1):37-41.

12. Mikučionienè D. the influence of structure parameters of weft knitted fabrics on propensity to pilling. Materials Science. 2009;15(4):335-338.

13. El-Dessouki HA. A study on abrasion characteristics and pilling performance of socks. Int Design J. 2010;4(2):229-234.

14. ISO 12945-2:2000. Textiles-Determination of fabric Propensity to surface fuzzing and to pilling-Part 2: Modified Martindale method.

15. ISO 12947-3:1998. Textiles-Determination of the abrasion resistance of the fabrics by Martindale Method-Part 3: Determination of Mass Loss.

16. Saville BP. Physical Testing of Textiles. Cambridge: CRC Woodhead Publishing Limited; 1999. 336 p.

17. Akaydin M. Characteristics of Fabrics Knitted With Basic Knitting Structures From Combed Ring and Compact Yarn. Indian J of Fibre \& Text Res. 2009;34:26-30.

18. Hu J. Fabric testing. Cambridge: Woodhead Publishing; 2008. 424 p. 